\title{
Attitude toward vaccination against COVID-19 of high school students in Thailand
}

\author{
Janutta Rieantong \\ Janutta.fiat@gmail.com \\ Chollada Village Paholyothin Road 54/1 Saimai District Bangkok, Thailand
}

\begin{abstract}
Background: COVID-19 is a highly contagious disease that can spread rapidly, affecting many deaths. According to my current situation, people around the globe are facing a pandemic (COVID-19). Therefore, vaccination is very necessary because it will build another layer of immunity, at least to reduce the danger once it has been infected. Vaccination can reduce the pandemic of COVID-19.

Objectives: This study aims to assess related knowledge and factors influencing attitudes toward vaccination against COVID-19 of Thai students.

Materials and methods: The study was conducted using a questionnaire. A total of 1,000 students studying in Central provinces in Thailand participated. COVID-19 related knowledge toward following risk perception, confidence in government, and attitudes toward COVID-19 vaccination. Differences between outcomes and sociodemographic were analysed through independent t-test and the ANOVA. In addition, preventive behaviours were analysed by a generalized linear model.

Results: The students showed a low level of attitude towards vaccination following confidence in government, and risk perception against COVID-19, only in knowledge at a moderate level. However, it has been found that there is a causal relationship between attitudes towards vaccination following confidence in government, and risk perception against COVID-19. In the first COVID-19 pandemic situation, people did not know much about the symptoms or effects after being infected, making them less conscious of taking care of themselves. Nowadays, germs have mutations that allow them to spread more quickly and become more dangerous. Therefore, digital centres should disseminate accurate information to people in order to increase their self-awareness. In addition, the government's credibility that the vaccines we will receive are effective enough to prevent the spread of the disease and this can make people more inclined to get vaccinated.
\end{abstract}

Conclusion: The students showed a low level of attitude towards vaccination following confidence in government, and risk perception against COVID-19, only in knowledge at a moderate level.

Keywors: COVID-19; vaccination 


\section{Introduction}

According to the World Health Organization report, COVID-19 is an infectious disease caused by the newly discovered coronavirus prior to its pandemic in Wuhan, China in 2019. Nowadays, it is still a public health crisis in countries around the world. The World Health Organization has received 171,916,673 confirmed cases as of June 6,2021, with approximately 3,575,505 deaths. This information may be understated. Some coronaviruses do not show symptoms in patients that it can cause community outbreaks in more than 222 countries around the world.

Situation in Thailand from disease surveillance from January 13,2020 until now (3 June 2021), we found a total of 165,462 confirmed cases of the new coronavirus, with 1,107 deaths. Outbreaks in Bangkok and its vicinity have been increasing since April last year. Places with a high risk of outbreaks within the country, such as places where large groups of people are gathered (schools, entertainment venues, restaurants, and so on).

At this moment, scientists have invented the COVID-19 vaccine that there are many brands to choose from, which reduce the risk of SARS-CoV-2 infection by working with the body's natural defences to safely develop immunity. It takes our body several weeks to build immunity after vaccination. After being vaccinated, some people develop various symptoms such as weakness, low-grade fever, nausea and vomiting, some of which develop thromboembolic or temporary paralysis. When the situation has been revealed to the public, some infected people or the population are afraid or unsure of vaccination. Therefore, there are campaigns to persuade more people to be interested and receive the COVID-19 vaccine.

It could be seen that vaccination had both advantages and disadvantages. The benefit was that our bodies were immune to this new virus, however, we might experience some side effects that might make vaccinated people feel sick and had other symptoms. Consequently, the researcher was interested in studying the factors affecting students' willingness to receive vaccination in order to find ways that could promote attitudes towards COVID-19 vaccination, including factors related to students' level of knowledge about the COVID-19 situation, attitudes and confidence in the public sector to reduce the spread and control the disease quickly at the household and community level.

\section{Methods}

This was a cross-sectional observational study. An online questionnaire was purposely developed and made available through Google Forms between 27th May and 27th June 2021 secondary students in Central provinces, Thailand, were invited to participate in completing an online questionnaire. A total of 1000 students participated. Infection control-related knowledge, attitudes toward infectious diseases, and preventive behaviours were assessed. All students enrolled in the academic year 2021 in public/private schools in the Central provinces of Thailand. The invitation was sent to local social media groups used by the students. In these emails, information about the study's objectives and the ethical guarantee of confidentiality and anonymity in the data collected as stated in the informed consent was explained. Participation was completely free and voluntary, and no personal data were collected from any participant.

\section{Instruments}

The questionnaire was developed based on a literature review including (1) information provided by and guidelines from the Department of Health, Ministry of Public Health in Thailand regarding Covid-19 and COVID-19 vaccine. In addition, (2) studies already performed on the same topic in other countries where several common items were used to assess each of the dimensions analysed in this study. The proposed items were then grouped, and redundant items were removed. A preliminary version of the instrument was reviewed by two infection control specialists to validate its content. A pretest was then performed with a small sample of high school students to test for comprehension and difficulty. All the questions remained without modifications. Finally, the psychometric characteristics of the questionnaires were tested, as described in the statistical analysis subsection. The final version of the questionnaire contained 28 questions; the first six questions about socio-demographic data (sex, educational level, Faculty interested, scientific area, congenital disease and influence of parents) and 22 items were divided into four sections.

COVID-19-related knowledge: This section consisted of 15 questions related to the basic knowledge of COVID-19 and vaccination. The participants were asked to choose only one correct answer for choices (True and False). One point was assigned to each correct answer while providing an incorrect answer received 0 points. The sum of all items was made; higher scores corresponding to a higher level of knowledge. The score varies from 0 to 15 , greater than or equal to 12 as a good level, greater than 9 but less than 12 as a moderate level, and less than 9 as a poor level.

Risk perception of Getting COVID-19: This section comprised four questions, and the response categories consisted of a five-point Likert scale ( 1 for never, 2 for hardly, 3 for sometimes, 4 for usually, and 5 for always) with the highest score corresponding to more positive attitudes toward preventive behaviours. The participants were asked to choose the number based on their practices and honestly. A sum of all the items within each factor was made to obtain a score. The "Attitudes toward preventive behaviours" varied from 1 to 20 , greater than or equal to 16 as a good level, greater than 12 but less than 16 as a moderate level, and less than 12 as a poor level.

Confidence in the government in handling the pandemic: This scale included two questions related to level of confidence in handling the pandemic. The students were asked to choose the number for a question ( 1 for very low, 2 for low, 3 for moderate, 4 for high, and 5 for very high). A high score on this scale indicated a good level of confidence in handling the pandemic, ranging from 1 to 10 , with greater than or equal to 8 as a good level, greater than 6 but less than 8 as a moderate level, and less than 6 as a poor level.

Attitude toward COVID-19 Vaccination: this scale referred to the willingness to be vaccinated against COVID-19. This item was answered using a five-point scale (From 1-Very low to 5- Very high). A high score on this scale indicated good preventive behaviours, ranging from 1 to 5, with greater than or equal to 4 as a good level, greater than 3 but less than 4 as a moderate level, and less than 3 as a poor level.

Ethical Considerations: this research used an anonymous data collection method to collect data from students who can access the internet and belong to social media groups in Central provinces in Thailand, by using Google Form. The invitation was sent to various social media groups. On these invitations, information about the study's objectives and ethical guarantee of confidentiality and anonymity of the data collected as stated in the informed consent was explained. Participation was completely free and voluntary, and no personal data were collected from any participant.

\section{Statistical analysis}

The analysis was performed using SPSS for Windows, version 26.0. To analyse the psychometric of infection and prevention control: personal factors, knowledge, attitudes, environment and behaviours characteristics of the scales, an exploratory factor analysis, using principal component analysis with varimax rotation, was carried out. The descriptive studies were presented in absolute (n) and relative (\%) frequencies, mean (M), and standard deviations (SD). To assess the differences between the outcome variables (personal factors, knowledge, risk perception, 
confidence in the government and attitude toward COVID-19 Vaccination) and the sociodemographic characteristics, considering the sample size, independent t-tests and the ANOVA were used, as appropriate. Pearson's correlation calculated the correlations between the outcomes of the study. Lastly, a generalized linear model was calculated to determine the predictive variables of the preventive behaviours. Exp $(\beta)$ and the respective $95 \%$ confidence intervals $(95 \% \mathrm{CI})$ were presented. Statistical significance was defined as $\mathrm{p}<0.05$.

\section{$\underline{\text { Results }}$}

This study comprised a total of 1,000 students. The sociodemographic characteristics of the sample are presented in Table 1. Most students were female $(n=797,79.7 \%)$. Most students' year levels were Grade $12(n=526,52.6 \%)$ followed by Grade $11(n=256,25.6 \%)$ and Grade $10(n=218,21.8 \%)$ respectively. Most participants had no congenital disease $(n=853,85.3 \%)$.

Regarding knowledge about COVID-19, students revealed good knowledge about COVID-19, correctly answering a mean of 11.33 (S.D.=1.75) questions in a total of 15 . Female students showed higher knowledge scores $(\mathrm{M}=11.44, \mathrm{SD}=1.73)$ than male students $(\mathrm{M}=10.89$, $\mathrm{SD}=1.78)$. Year level of Grade 11 showed the highest COVID-19 related knowledge score of 11.5 (SD=1.87). Likewise, students who had congenital disease had the highest score of $14.45(\mathrm{SD}=1.77)$.

Students showed a low-level risk perception of getting COVID-19 with an average score of 9.53 from 20 full scores. Female students had a better attitude $(M=9.63, S D=3.91)$ than male students $(M=9.1, S D=4.04)$. Grade 11 students had the highest level of attitude 9.74 ( $S D=3.94)$. In addition, students who had congenital disease had a better attitude $(\mathrm{M}=10.15, \mathrm{SD}=3.92)$ than those who did not have any underlying disease $(\mathrm{M}=9.42, \mathrm{SD}=3.94)$

Level of confidence in the government handling the pandemic, for male students $(\mathrm{M}=2.02, \mathrm{SD}=1.17)$ is higher than female students $(\mathrm{M}=1.83, \mathrm{SD}=1.02)$. Grade 10 students had the highest confidence in government $(\mathrm{M}=1.96, \mathrm{SD}=1.10)$ among the 3 grade levels. Students who were with congenital disease had higher confidence in the government $(\mathrm{M}=1.92, \mathrm{SD}=1.13)$.

In part of their attitude toward COVID-19 vaccination, students showed unfavourable attitudes toward COVID-19 vaccination with an average score of 1.87 from 5 full scores. Male students showed higher scores $(M=2.02, \mathrm{SD}=1.17)$ than female students' (M=1.83, SD=1.02). Grade 10 students showed the highest scores of $1.96(\mathrm{SD}=1.1)$. Students who had congenital disease had higher scores $(\mathrm{M}=1.92, \mathrm{SD}=1.13)$ than the one who didn't (M=1.86, $\mathrm{SD}=1.04)$. (Table 1).

Table 1 The sociodemographic characteristics and outcomes of the sample

Differences in outcomes according to the sociodemographic characteristics of participants $(\mathrm{N}=1000)$

\begin{tabular}{|c|c|c|c|c|c|c|c|c|c|}
\hline \multirow[t]{2}{*}{$\begin{array}{l}\text { Sociodemographic } \\
\text { Characteristic }\end{array}$} & \multirow[b]{2}{*}{$\mathrm{N}(\%)$} & \multicolumn{2}{|c|}{$\begin{array}{c}\text { Knowledge about } \\
\text { COVID-19 } \\
\text { (Range } 0-15 \text { ) }\end{array}$} & \multicolumn{2}{|c|}{$\begin{array}{l}\text { Risk perception of } \\
\text { Getting COVID-19 } \\
\quad \text { (Range 4-20) }\end{array}$} & \multicolumn{2}{|c|}{$\begin{array}{l}\text { Confidence in } \\
\text { Government in } \\
\text { Handling the } \\
\text { pandemic (Range } \\
1-10)\end{array}$} & \multicolumn{2}{|c|}{$\begin{array}{l}\text { Attitude toward } \\
\text { COVID-19 } \\
\text { Vaccination } \\
\text { (Range 1-5) }\end{array}$} \\
\hline & & Mean & S.D. & Mean & S.D. & Mean & S.D. & Mean & S.D. \\
\hline \multicolumn{10}{|l|}{ Gender } \\
\hline Female & 797 (79.7) & 11.44 & 1.73 & 9.63 & 3.91 & 3.90 & 1.73 & 1.83 & 1.02 \\
\hline Male & $203(20.3)$ & 10.89 & 1.78 & 9.10 & 4.04 & 4.13 & 1.89 & 2.02 & 1.17 \\
\hline \multicolumn{10}{|l|}{ Year Level } \\
\hline Grade 10 & $218(21.8)$ & 11.17 & 1.60 & 9.35 & 3.76 & 4.11 & 1.86 & 1.96 & 1.10 \\
\hline Grade 11 & $256(25.6)$ & 11.50 & 1.87 & 9.74 & 3.94 & 3.86 & 1.78 & 1.93 & 1.08 \\
\hline Grade 12 & $526(52.6)$ & 11.31 & 1.75 & 9.49 & 4.02 & 3.92 & 1.71 & 1.81 & 1.02 \\
\hline \multicolumn{10}{|c|}{ Having Congenital Disease } \\
\hline \multirow[t]{2}{*}{ Yes } & & & & & & & & & \\
\hline & $147(14.7)$ & 11.45 & 1.77 & 10.15 & 3.92 & 4.10 & 1.91 & 1.92 & 1.13 \\
\hline \multirow[t]{2}{*}{ No } & & & & & & & & & \\
\hline & $853(85.3)$ & 11.31 & 1.75 & 9.42 & 3.94 & 3.92 & 1.74 & 1.86 & 1.04 \\
\hline \multirow[t]{2}{*}{ Total } & & & & & & & & & \\
\hline & $1,000(100)$ & 11.33 & 1.75 & 9.53 & 3.94 & 3.94 & 1.76 & 1.87 & 1.06 \\
\hline
\end{tabular}


The analysis of the correlations between the outcomes of the study - knowledge, risk perception, level of confidence in the government and attitude toward vaccination - revealed the existence of both positive (risk perception-level of confidence) and negative (knowledge) and statistically significant correlations between the risk perception and willingness of people related to COVID-19 ( $\left.\mathrm{r}=.094^{* *}, \mathrm{p}<0.01\right)$, level of confidence toward the heartiness of getting COVID-19 vaccine $\left(r=.515^{* *}, \mathrm{p}<0.01\right)$. (Table 2$)$

Table 2 The analysis of the correlations between the outcomes of the study - knowledge, risk perception, level of confidence in the government and attitude toward vaccination

\begin{tabular}{|c|c|c|c|c|}
\hline \multicolumn{5}{|c|}{ Pearson's correlation coefficient between the study outcomes } \\
\hline Variable & $\begin{array}{c}\text { Knowledge about } \\
\text { COVID-19 }\end{array}$ & Risk Perception & $\begin{array}{c}\text { Level of Confidence in } \\
\text { Government }\end{array}$ & $\begin{array}{c}\text { Attitude toward } \\
\text { vaccination }\end{array}$ \\
\hline Knowledge about COVID-19 & 1 & & & \\
\hline Risk perception & $.099 * *$ & 1 & & \\
\hline Level of Confidence in Government & $-.178 * *$ & .050 & 1 & \\
\hline Attitude toward vaccination & $-.098 * *$ & $.094 * *$ & $.515^{* *}$ & 1 \\
\hline$* *$ Correlation is significant at 0.01 & & & & \\
\hline
\end{tabular}

Results from the generalized linear model indicated that the gender of students $($ Beta $=.053, \mathrm{p}<0.01)$, knowledge about COVID-19 $($ Beta $=-.012$, $\mathrm{p}<0.01$ ) had a statistically significant effect on the willingness of students.

(Table 3)

Table 3 Generalized linear model predicting attitude toward COVID-19 vaccination

\begin{tabular}{|l|c|c|c|c|c|c|}
\hline \multicolumn{1}{|c|}{ Variable } & B & SE & Sig & Beta & \multicolumn{2}{c|}{$95 \%$ Confidence Interval } \\
\cline { 3 - 7 } & & & & & Lower bound & Upper bound \\
\hline Gender & .139 & .072 & .054 & .053 & -.002 & .280 \\
\hline Knowledge about COVID-19 & -.007 & .017 & .677 & -.012 & -.040 & .026 \\
\hline Risk Perception of Getting COVID-19 & .020 & .007 & .006 & .076 & .006 & .035 \\
\hline $\begin{array}{l}\text { Level of Confidence in Government handling } \\
\text { the Pandemic }\end{array}$ & .305 & .017 & .000 & .507 & .272 & .337 \\
\hline
\end{tabular}

\section{Discussion}

The students who answered this questionnaire had a moderate knowledge score. Female students scored higher than men because men's health care or health concerns were less than women's [1]. This includes a society of men who have to go out for other activities that have a negative effect on their bodies, making them less likely to get information [2]. In the upper secondary level, it was found that Grade 11 students were the most knowledgeable about this disease, probably because Grade 10 students needed time to adjust from lower secondary school to upper secondary school, so it was important to spend a lot of time in this phase. Grade 12 students spent most of their time reading books to prepare for university entrance exams, making Grade 11 students able to find or obtain more information about COVID-19 than others. Students with congenital disease were more knowledgeable about COVID-19. This may be due to complications during the illness that could make the condition worse [3]. This group must be especially careful for their own safety.

In terms of risk perception, women had a higher average score than males due to their greater attention to prevention and vigilance [4]. Grade 11 students also had higher scores on risk perception than other grades because they had a higher score in knowledge against COVID-19 than other grades, which affected the perception of risk[4]. We will be able to prevent and know how dangerous this disease was. In addition, students with congenital disease had more awareness than normal students. 
From this research, it was found that the respondents had a low level of confidence in the government. As youth groups were dissatisfied with the government's work before the COVID-19 outbreak, there were several protests against the regiment [9,10,11]. The epidemic repeated two to three times, this is due to management deficiencies and lack of credibility in vaccine administration policies [12]. There were only two vaccine options, which were Sinovac and AstraZeneca. News about vaccination side effects mentioned ineffective vaccines had a number of impacts, both economically and socially $[13,14]$.

Students who answered this questionnaire showed a low willingness to receive the COVID-19 vaccine since the level of confidence in the government was low and the vaccine options the government provided to the people were not enough. People were still unconvinced about the effectiveness of those vaccines. In addition, the COVID-19 vaccines were developed for such a short period of time, there was no information on long-term effects after vaccination. Elise Paul, Andrew Steptoe and Daisy Fancourt studied the intention to vaccinate against COVID-19 in the U.K. They found that a half of the population were willing to receive the vaccine, while those hesitant and reluctant to get it for some reason had expected side effects [15]. Roselinde Kessels, Jeroen Luyten and Sandy Tubeuf studied the willingness to vaccinate against COVID-19 in Belgium and found that 30 percent of people were willing to receive the vaccine COVID-19 due to concern about side effects [16].

\section{Limitation}

First, information gathered through the use of web platforms may be biased, especially within the domain of knowledge because there is no guarantee that the Internet is now widely used. Including the use of a lot of news from many sources, with some news agencies adding their own opinions, which may result in these students' receiving misinformation. The social impact of watching this might also be worthwhile. Think about that in keeping with the results obtained, although Thailand has a diverse group of people who are expected to have a significant impact on the thinking of today's students. Those students should use their knowledge and reasoning to analyse the correct facts of the information they have been given.

\section{Conclusion}

The students showed a low level of attitude towards vaccination following confidence in government, and risk perception against COVID-19, only in knowledge at a moderate level. However, it has been found that there is a causal relationship between attitudes towards vaccination following confidence in government, and risk perception against COVID-19. In the first COVID-19 pandemic situation, people did not know much about the symptoms or effects after being infected, making them less conscious of taking care of themselves. Nowadays, germs have mutations that allow them to spread more quickly and become more dangerous. Therefore, digital centres should disseminate accurate information to people in order to increase their self-awareness. In addition, the government's credibility that the vaccines we will receive are effective enough to prevent the spread of the disease and this can make people more inclined to get vaccinated.

\section{References}

1. Health Promotion International.Gender differences in health information behaviour: a Finnish population-based survey. Oxford University Press. Issue 3/Volume 30. Available from : https://academic.oup.com/heapro/article/30/3/736/620016. [Last access: 20 Jun 2021]

2. Carol Vlassoff. Gender Differences in Determinants and Consequences of Health and Illness. Journal of Health, Population, and Nutrition. Available from :https://www.ncbi.nlm.nih.gov/pmc/articles/PMC3013263/. [Last access: 20 Jun 2021]

3. Centers for Disease Control and Prevention. People with Certain Medical Conditions. Available from : https://www.cdc.gov/coronavirus/2019-ncov/need-extra-precautions/ people-with-medical-conditions.html.[Last access: 20 Jun 2021]

4. Regina Ferreira Alves, Catarina Samorinha, José Precioso. Knowledge, attitudes and preventive behaviors toward COVID-19: a study among higher education students in Portugal. Journal of Health Research. Issue 4/ Volume 35. Available from : https://www.emerald.com/insight/content/doi/10.1108/JHR-07-2020-0254/full/html .[Last access: 20 Jun 2021]

5. BBC News. COVID-19 : Tawida Kamolvej "Disaster Goddess" looks at the phenomenon of "suing the government" in the crisis.

6. . Available from: https://www.bbc.com/thai/thailand-57787418.[Last access: 20 Jun 2021]

7. M.Tyler Boden, Howard Berenbaum.Emotional awareness, gender, and suspiciousness. Journal of Abnormal Psychology. Issue 2/ Volume 21. Available from: https://www.ncbi.nlm.nih.gov/pmc/articles/PMC2796829/.[Last access: 20 Jun 2021]

8. Fred Cicetti. Anxiety May Increase With Age. Available from: https://www.livescience.com/8452-anxiety-increase-age.html. [Last access: 20 Jun 2021]

9. Bangkok Hospital. Key Things To Know About COVID-19 Vaccines. Available from: https://www.bangkokhospital.com/en/content/know-well-before-getting-the-covid-19-vaccine. [Last access: 20 Jun 2021]

10. Thairath online. "Mob 20th February" settling in front of the parliament. Available from: https://www.thairath.co.th/news/politic/2036599. [Last access: 20 Jun 2021] 
11. Bangkok Business."Mob" is scheduled for a new rally at "Ratchaphrasong" on February 23 . Available from: https://www.bangkokbiznews.com/news/detail/923795. [Last access: 20 Jun 2021]

12. BBC NEWS. Students flash mob to the big rally of the "People's Council 2020.Available from: https://www.bbc.com/thai/thailand54741254 [Last access: 20 Jun 2021]

13. BBC NEWS. Thanathorn Juangroongruangkit delayed the government's vaccination with only 5,000 doses a day before admitting the 112 charge. Available from: https://www.bbc.com/thai/thailand-56560771. [Last access: 20 Jun 2021]

14. Thairath online. COVID-19 pushes "unemployment rises-debt increases" SMEs - tourism - new graduates "high risk". Available from: https://www.thairath.co.th/news/local/2102340. [Last access: 20 Jun 2021]

15. workpointToday. In the first six months of 2020, during the COVID-19 outbreak, more Thai people died from suicide. Available from: https://workpointtoday.com/06-27/. [Last access: 20 Jun 2021]

16. Elise Paul, Andrew Steptoe, Daisy Fancourt. Attitudes towards vaccines and intention to vaccinate against COVID-19: Implications for public health communications. THE LANCET Regional Health. Volume 1. Available from: https://www.thelancet.com/journals/lanepe/article/PIIS2666-7762(20)30012-0/fulltext.[Last access: 20 Jun 2021]

17. Roselinde Kessels, Jeroen Luyten, Sandy Tubeuf. Willingness to get vaccinated against Covid-19 and attitudes toward vaccination in general. Elsevier Public Health Emergency Collection. Available from: https://www.ncbi.nlm.nih.gov/pmc/articles/PMC8149196/. [Last access: 20 Jun 2021] 